\title{
Gender, Careers and Organisations
}

Current Developments in Banking, Nursing and Local Government

SUSAN HALFORD

MIKE SAVAGE

and

ANNE WITZ

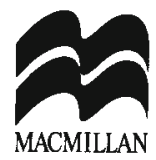




\section{2}

(C) Susan Halford, Mike Savage and Anne Witz 1997

All rights reserved. No reproduction, copy or transmission of this publication may be made without written permission.

No paragraph of this publication may be reproduced, copied or transmitted save with written permission or in accordance with the provisions of the Copyright, Designs and Patents Act 1988, or under the terms of any licence permitting limited copying issued by the Copyright Licensing Agency, 90 Tottenham Court Road, London W1P 9HE.

Any person who does any unauthorised act in relation to this publication may be liable to criminal prosecution and civil claims for damages.

The authors have asserted their rights to be identified as the authors of this work in accordance with the Copyright, Designs and Patents Act 1988.

First published 1997 by MACMILLAN PRESS LTD

Houndmills, Basingstoke, Hampshire RG21 6XS

and London

Companies and representatives

throughout the world

ISBN 978-0-333-60978-1

DOI 10.1007/978-1-349-25562-7

ISBN 978-1-349-25562-7 (eBook)

A catalogue record for this book is available from the British Library.

This book is printed on paper suitable for recycling and made from fully managed and sustained forest sources.

$\begin{array}{cccccccccc}10 & 9 & 8 & 7 & 6 & 5 & 4 & 3 & 2 & 1 \\ 06 & 05 & 04 & 03 & 02 & 01 & 00 & 99 & 98 & 97\end{array}$

Editing and origination by Aardvark Editorial, Mendham, Suffolk 


\section{Contents}

List of Tables and Figures iv

Preface v

Acknowledgements $\mathrm{x}$

1 Gender and Organisations: Theoretical issues 1

2 Researching Organisations 29

3 Restructuring Organisations, Changing People 64

4 Organisational Change and Career Restructuring 107

5 Gender, Strategy and Career Narratives 154

6 ( $\mathrm{Re}$ )presentations of 'Home' and 'Work' in Organisational Life

7 Organised Bodies: Gender, Sexuality and Workplace Culture 228

Conclusions 261

Appendix: Details of Interviewees $\quad 270$

$\begin{array}{ll}\text { Notes } & 274\end{array}$

Bibliography 276

$\begin{array}{ll}\text { Index } & 287\end{array}$ 


\section{List of Tables and Figures}

Table 2.1 Distribution of white collar staff by grade and sex: Southtown District Council, February 1991 and March 1986

Table 2.2 Proportion of workers in different grades who are women: Midcity Council 1991

Table 2.3 Full-time APT\&C staff by grade and sex: Housing Department, Midcity Council

Table 2.4 Gender and grades: Midcity Sellbank 1991

Table 2.5 Gender and grades: Southtown Sellbank 1991

Table 2.6 Nursing workforce by grade and gender: Southtown 1991

Table 2.7 Nursing workforce by grade and gender: Midcity 1991

Table 4.1 Career routes in banking

Table 4.2 Gender of previous job-holders, by seniority: Sellbank

Table 4.3 Respondents thinking they had a job or career, by sex and sector

Table 4.4 The post-Salmon bureaucratic career in nursing

Table 6.1 'Are the following activities important to you personally?': \% claiming 'important' or 'very important'

Table 6.2 Childcare arrangements by gender and sector

Figure 2.1 Southtown Hospital: corporate structure

Figure 2.2 Southtown Hospital: clinical directorate structure

Figure 2.3 Midcity Hospital: organisational structure

Figure 3.1 Extract from Midcity's Annual Report

Figure 4.1 The traditional banking career

Figure 4.2 The restructured banking career

Figure 4.3 Career paths in local government finance and housing 


\section{Preface}

In this book we examine the relationship between gender, careers and organisations in Britain during the 1980s and early 1990s. On the surface this seems a period of dramatic change. Until the 1970 s women were usually located firmly at the bottom of most organisational hierarchies. In some cases women were still expected to leave work on marriage, in most cases they were expected to leave work when they had children, and they were nearly always employed in jobs that allowed them little opportunity for job mobility or promotion.

In their influential study of gender and white collar work carried out between 1979 and 1981, Crompton and Jones (1984) suggested that traditional forms of gender inequality were likely to change as growing numbers of women working in white collar jobs began to seek promotion into more senior posts. In the 1980s and 1990s there was indeed considerable evidence that the position of women in British organisations was improving. During this period the number of women in the labour market increased, as it has done for much of the post-war period, but more importantly women began to acquire credentials at an increased rate (Crompton and Sanderson, 1990) and have consequently come to make up a significant proportion of new entrants to professional jobs (Crompton, 1995; Fielding, 1995). There is also considerable evidence that increasing numbers of women are being promoted to senior management level within many organisations (Davidson and Cooper, 1992). Connected to these changes, and following from the Equal Pay Act and the Sex 
Discrimination Act in $1975^{1}$, many organisations have developed an array of additional, non-statutory equal opportunity policies that aim to encourage changes in organisational practice, in order to improve the position of women workers (as well as that of other under-represented groups). Indeed, in 1991 a large group of major employers banded together under the auspices of the government-backed organisation Business in the Community to launch 'Opportunity 2000', a joint initiative designed specifically to improve women's career opportunities.

There are, however, plenty of reasons not to be swept away by these sorts of observation. It is easy to find counter examples that testify to the persistence of gender segregation and inequality. For example, although growing numbers of women are becoming qualified in professions such as law and accountancy, some of the occupational areas in which women have traditionally used credentialism to secure professional employment have been radically restructured and/or contracted, as in for example teaching (Crompton and Sanderson, 1990) and nursing (Walby et al., 1994). There is also strong evidence that a 'glass ceiling' effect prevents women from moving into the most senior jobs within organisations (Chapman, 1989) and that well-credentialed women are channelled into specialist 'niche jobs' that prevent them from using their skills, acquired expertise and experience to their full potential (Crompton and Sanderson, 1990; Savage, 1992; Crompton, 1995). These 'niche' jobs often entail using professional skills but not managing other professionals. Furthermore, many of the new 'women's jobs' that have appeared in recent years involve temporary or part-time contracts offering women only marginal career status and opportunities. Finally, whatever the statements of intent, equal opportunity policies are not always implemented in practice (Halford, 1992) and even when they are implemented may have ambiguous and possibly contradictory implications for women's position; for example, targeting childcare provisions at women could be seen to reinforce gender-specific 'familial' roles in an organisational context (Cockburn, 1991).

To what extent, then, are gender relations within organisations really changing? This book explores the changing position 
of women and men within one high street bank and two local authorities, and on the nursing staff of two hospitals. Initially, we wanted to compare men's and women's career paths in these different organisational settings (partly along the lines pioneered by Crompton and Jones, 1984), and were most interested in the gendered experience and meaning of career, and in comparing the career trajectories of men and women. This interest lies at the heart of this book. However, the study of 'career' pathways, narrowly defined, has become only one aspect of a much broader analysis. From the outset we were also interested in the organisational practices and cultures that affected careers within our case study organisations. Indeed, one of our aims was to shift attention away from movement between occupations which has been the main focus of social mobility research - to movement within organisations. As our research progressed, it became even clearer that in order to understand changing patterns of career mobility, it was not enough just to compare the movement of men and women between different jobs within organisations. It was also vital to consider the pervasive gendering of a whole variety of organisational processes that define the terrain on which mobility takes place. After all - to rehearse a tension that has always characterised sociological research in this area - occupational mobility cannot be understood just by looking at the individuals who are (or are not) mobile but needs to be analysed in terms of the positions between which people move and through which the nature and meaning of mobility are understood and contextualised (see Savage, 1996, for further discussion).

This raises a number of questions. How do the meaning, status and power of jobs change as women move into them (Reskin and Roos, 1990)? How does the restructuring of organisations affect job and career opportunities within them? How, in turn, is organisational change related to gender divisions and gendered careers? Thus the analysis of women's and men's careers that we elaborate in this book is embedded within a much broader inquiry into the gendering of contemporary organisations and into an analysis of the dynamics of organisational change. This latter point raises far more than a 
simple consideration of the changing proportions of men and women in different jobs or following different career paths. Rather, recent organisational restructuring has changed the ways in which gender is embedded in various organisational roles and activities. This in turn means that the terrain on which career mobility takes place has itself been redefined. Our examination of these issues is found in Chapter 3, where we provide an account of the gendered restructuring of the organisations we studied and develop our theoretical argument about the nature of restructuring.

In Chapter 4 we explore the consequences of such change for women's and men's career paths. We show that restructuring has significantly redefined the 'career', and provide some evidence from our organisations that traditional 'male' careers are being threatened whilst emergent 'female' careers are being formed (although the reader will see that there are significant differences between the organisations).

Through our discussions in Chapters 3 and 4 it becomes clear that recent organisational restructuring has changed the 'personal' qualities and attributes that are valued in our organisations, and hence that are rewarded in career terms. Of course, this has major implications for people working in these organisations. In Chapter 5 we focus directly on individuals' responses to recent change, their interpretations of what was expected of them and their reflections on their place within the organisations in which they worked.

This raises some broader questions. As one would expect, when individuals discuss their 'careers', they do so in the context of broader concerns and social relationships. Perhaps the most widely remarked on instance of this within popular and academic accounts of gender and careers concerns the relationship between domestic and familial ties and employment careers. In Chapter 6 we explore individuals' accounts of these relationships and the ways in which these are being (re)shaped by organisational change. We consider both the practical arrangements between 'home' and 'work' commitments, and the symbolic ways in which the domestic, and particularly the 'maternal', are embedded in organisational life. This leads us to 
a more abstract discussion, at the end of Chapter 6 , about the ways in which embodiment - specifically gendered embodiment - features in organisational discourse and practice. These points are extended in Chapter 7 , where we take up the issue of sexuality, exploring the complex interaction of gender and sexuality in workplace relationships and hierarchies through a notion of an organisational 'politics of the body'.

The reader will now see how this book has finally ended up as a rather broad inquiry into the linkages between gender and organisation. In order to orient readers to the many issues which this book takes up, we provide two introductory chapters. Chapter 1 situates our analysis within broader theoretical debates about the relationship between gender and organisations. This introduction reflects on the various issues and theoretical perspectives within contemporary debates on gender and organisation, and provides a rationale for the particular positions we take in this book. Chapter 2 presents an introduction to the case study organisations and to the research methods we used in our study. The fact that we have included many of the basic details of our research in Chapter 2 means that subsequent chapters can be more fully devoted to developing points of substantive interest. Readers who skip this chapter (which is not, strictly speaking, central to the arguments we make) should bear in mind that basic factual material about the organisations and occupations we studied, as well as a discussion of our research methods, is contained in this chapter and that crossreference to it might be necessary.

Overall, perhaps the single most important contribution that we hope this book makes is to bring a wealth of new empirical material to bear on the many hotly contested current debates about gender and organisation. As far as possible, we have allowed the people we spoke to during the course of our research to comment on the changes they saw happening around them and to them. It has become commonplace within the social sciences to point out that people are knowledgeable agents (Giddens, 1984), and in this book we take this point very seriously by making people's accounts central to our study. 


\section{Acknowledgements}

First and most importantly, we would like to thank the Economic and Social Research Council for funding this project (grant number R00023277301). Readers will detect that the project changed somewhat as it progressed, in terms of both institutional support and intellectual direction, and we are grateful that the ESRC as it was constituted then was able to fund and support necessary modifications. The project was not the easiest to co-ordinate, since Susan Halford was initially based at Sussex University (later at Southampton University), Mike Savage at Keele University (later at the University of North Carolina and later still at Manchester University), and Anne Witz at Birmingham University (later at RuhrUniversität Bochum, Germany). This situation led to British Telecom earning a good commission from our project, but more seriously it meant that we have to thank a number of London-based friends who lent us their houses and flats for our regular meetings. Chris Howlett and Claire Higginson gave us the benefit of their flat in Hackney, whilst Caron Jones offered a nearby alternative in Walthamstow.

We would also like to thank the organisations that allowed us access and the individuals who helped our research, whether by answering questions, filling in questionnaires or being interviewed in depth. We cannot name any individuals, since this would reveal the identity of the organisations involved, but we do wish to record our gratitude to everyone to whom we spoke and who helped us in the course of our research.

One of the distinctive features of our project was that we invited an 'expert panel' to guide us in the preparation and conduct of our research. This expert panel comprised both academics, people working in policy fields and members of the case study organisations 
themselves, and allowed a rare opportunity for the interplay of academic and policy-oriented ideas. We cannot name all the participants, since again this would reveal the identities of the organisations, but we can thank Sara Arber (University of Surrey), Steven Bubb (Association of Metropolitan Authorities), Margery Povall, Ed Puttick (Equal Opportunities Commission) and Dianah Worman (Institute of Personnel Management). Many other people have also given advice, comments and support of various sorts: we would like to single out Lisa Adkins, Sarah Cant, Rosemary Crompton, Sue Gilbert, Gill Court, Joy Kendrick, Dave Laflin, Pauline Leonard, Ann-Therese Lotherington, Linda McDowell and Jane Wills.

Versions of parts of this book have been presented at a variety of conferences and seminars. We would like to thank everyone who gave us feedback on these occasions. Susan Halford presented papers in the Geography Departments at Southampton University, Reading University and Cambridge University; at the Social Science Research Institute in Tromsø, Norway; and at the Institute of British Geographers Annual Conference. Mike Savage presented papers to the Rural Economy and Society Study Group Annual Conference; the British Association Conference at Keele University; the Department of Sociology and Social Anthropology, Keele University; and the Department of Sociology, Buckinghamshire College of Higher Education. Anne Witz presented papers to a National Day School on sexual harassment in the National Health Service, University of Central Lancashire; the Faculty of Social Sciences Seminar, University of Plymouth; a conference on 'Organisations, Gender, and Power' organised by the Industrial Relations Research Unit, Univeristy of Warwick; and a workshop on 'Transformation in Gender Relations', Sozialforschungsstelle Dortmund, Germany. Susan Halford and Mike Savage gave papers to the 9th Urban and Regional Change Conference, Sheffield University; the Gender Studies Institute, London School of Economics; and the Department of Sociology and Social Policy, Southampton University. Susan Halford, Mike Savage and Anne Witz gave a paper to the British Sociological Association Annual Conference, University of Central Lancashire.

Finally, many thanks to Frances Arnold and Catherine Gray at Macmillan Press for their enthusiasm, support and patience. 